\title{
Acute Blood Transfusion Reactions in Pregnancy, an Observational Study from North Eastern Nigeria
}

Umar Nasiru Ibrahim ${ }^{1 *}$, Nasiru Garba ${ }^{1}$ and Idris Musa Tilde ${ }^{2}$

${ }^{1}$ Department of Obstetrics and Gynaecology, Federal Medical Centre, Azare, Nigeria

${ }^{2}$ Department of Pathology, Federal Medical Centre, Azare, Nigeria

\begin{abstract}
Blood transfusion is one of the key interventions in emergency obstetrics care and is known to save lives, however complications do occur. Pregnancy has certain peculiarities, which includes physiological changes, development of antigens against red cells, leucocytes and platelets. History of previous transfusion is common in pregnancy. The aim of this study is to find the incidence, presentations, types and risk factors for developing acute transfusions reaction in pregnancy.
\end{abstract}

Materials and methods: Retrospective study of all blood transfusions in pregnancy between January to December 2012 at Federal Medical Centre Azare, Nigeria.

Results: 1602 pregnant women received blood transfusion out of 15213, given a transfusion rate of $10.5 \%$ the mean age and parity were $28.3 \pm 4.2$ years and $6 \pm 1$ respectively.

Acute reactions were found in $26.3 \%$. Non heamolytic febrile reaction accounts for $47.7 \%$. Allergic uticaria account for $24.5 \%$

There was a significant relationship between stored blood and transfusion reactions, similarly, significant relationship was found between previous history of transfusion and transfusion reactions, but no difference was found between rise and full cross match and uncross match but $\mathrm{ABO}$ compatible blood in developing transfusion reactions.

Conclusions: As blood transfusion alternatives are not readily available or not practical in pregnancy hemovigilance is the key to making blood transfusion safer.

Keywords: Acute transfusion reactions; Pregnancy

\section{Introduction}

Blood transfusion is an important intervention in the management of pregnancy complications in sub-Saharan Africa, where Anaemia, Sepsis, Obstetrics heamorrhage, obstructed labour and complications of abortions are common. Blood may be life saving and therefore, recommended as a life saving measure to reduce maternal deaths [1]. Complications of blood transfusion are well known, they may be classified based on time of onset as acute or delayed or based on etiology - Immunological or non Immunological.

Studies have shown that up to $20 \%$ of transfusion may result in some complications [2], most of these studies are conducted in non pregnant subjects but pregnancy poses a special challenge as immune response in pregnancy is different from the non pregnant state and this may possibly affect the nature or onset of complications, as pregnancy is known to cause formation of red cells allo antibodies [3].

Advances in transfusion medicine, coupled with availability of blood products substitutes had help in reducing transfusion rates in the western world but such cannot be said to be true in Africa where rates up to $37 \%$ in obstetrics emergencies have been reported [4].

North Eastern Nigeria has the highest maternal mortality ratio in the country with figures upto $1700 / 100,000$ live births [5]. Obstetrics complications are common and so is blood transfusion, but studies on blood transfusion in general and specifics such as acute blood transfusion reactions in pregnancy are rare. Therefore the aim of this study is to determine the incidence, types, clinical presentation and risk factors for acute transfusion reactions in pregnancy.

\section{Materials and Methods}

The study was conducted over a period of 12 months from January to December, 2012 at Federal Medical Centre, Azare. A sub-urban town in North Eastern Nigeria, the hospital is a tertiary health institution serving a population of nearly 3 million people. All pregnant women that were transfused during the period were included in the study Retrospective analysis of their case records both in the obstetrics and laboratory department of the hospital was carried out. Data relating to age, parity, indication for transfusion, numbers of the units transfused, duration of blood storage, adverse reactions and laboratory analysis result following an adverse reaction were collected. The results were analyzed using SPSS Version 16.

Sixteen cases were excluded as the symptoms they developed were not attributed to the transfusions. The study was approved by the hospital ethical committee.

\section{Results}

15213 pregnant women were seen during the period under review

*Corresponding author: Umar Nasiru lbrahim, Department of Obstetrics and Gynaecology, Federal Medical Centre, Azare, Nigeria, E-mail: unibrahim2000@yahoo.co.uk

Received May 27, 2013; Accepted June 27, 2013; Published June 30, 2013

Citation: Ibrahim UN, Garba N, Tilde IM (2013) Acute Blood Transfusion Reactions in Pregnancy, an Observational Study from North Eastern Nigeria. J Blood Disorders Transf 4:145. doi:10.4172/2155-9864.1000145

Copyright: (c) 2013 Ibrahim UN, et al. This is an open-access article distributed under the terms of the Creative Commons Attribution License, which permits unrestricted use, distribution, and reproduction in any medium, provided the original author and source are credited. 
and 1602 cases were transfused given a transfusion rate of $10.5 \%$. The mean age of the women who were transfused was $28.3 \pm 4.2$ years, and the mean parity was $6 \pm 1$. Abruptio placenta and placenta prevea were the commonest indication for transfusion constituting $37.2 \%$ and $20.5 \%$ respectively (Table 1 ).

Acute reactions were seen in 421 patients $(26.3 \%)$ most of the complications are mild with no record of fatalities (Table 2). The commonest is non heamolytic febrile reaction $47.7 \%$, followed by Allergic Uticaria (24.5\%). A statistically significant difference exist between stored blood $>24$ hours and unstored blood less than 24 hours, as only 5 out of 142 patient that received unstored (fresh) blood reacted as against 216 reactions from 1460 stored blood (Odd ratio 10.92, $\mathrm{p}<0.00001, \mathrm{C} 195 \%)$.

Women who had previous history of transfusion are susceptible to react to blood transfusion as against those that had no previous history of blood transfusion, as a statistically significant difference was found among the 221 out of 646 who reacted (history of previous transfusion) as against 200 out of 956 who reacted among women that had no previous history of transfusion (Odd ratio 1.97 , CI 95\%, p<0.0001).

There is no statistical difference between a blood that was cross match fully for 2 hours as against uncross match but same ABO blood group or cross match blood for less than 2 hours (Table 3 ).

Multigrividae are more likely to develop acute transfusion reaction than primigrividae (Table 4). Four patients had received massive blood transfusion (replacement of their total blood volume within 24 hours) and two of them have manifested acute transfusion reactions.

\section{Discussion}

Despite the clamour to reduce the rate of blood transfusion on one hand, there is a greater need to treat obstetrics emergencies so as to reduce maternal morbidity and mortality, and blood is one of the essential tools especially in sub-Saharan Africa. Therefore, at the moment, the choice is to make blood transfusion safer, and some of the ways of doing so is through haemovigilance so as prevent, identify reports and treat reactions where they occur [6]. Blood transfusion

\begin{tabular}{|c|l|c|c|}
\hline S/No & \multicolumn{1}{|c|}{ Indications } & №. & (\%) \\
\hline $\mathbf{1}$ & Abruptio Placenta & 597 & 37.2 \\
\hline $\mathbf{2}$ & Placenta Prevea & 328 & 20.5 \\
\hline $\mathbf{3}$ & Severe Anaemia & 284 & 17.7 \\
\hline $\mathbf{4}$ & Uterine Atony & 150 & 9.4 \\
\hline $\mathbf{5}$ & Complications of Abortions & 102 & 6.4 \\
\hline $\mathbf{6}$ & Ruptured Uterus & 70 & 4.4 \\
\hline $\mathbf{7}$ & Sepsis & 45 & 2.8 \\
\hline $\mathbf{8}$ & Others $\quad$ Total & $\mathbf{1 6 0 2}$ & 1.6 \\
\hline & & 100 \\
\hline
\end{tabular}

Table 1: Abruptio placenta and placenta prevea were the commonest indication for transfusion constituting $37.2 \%$ and $20.5 \%$ respectively

\begin{tabular}{|c|l|c|c|}
\hline S/№ & \multicolumn{1}{|c|}{ Reactions } & №. & $\mathbf{( \% )}$ \\
\hline $\mathbf{1}$ & non heamolytic febrile reaction & 201 & 47.7 \\
\hline $\mathbf{2}$ & Allergic Uticaria. & 103 & 24.5 \\
\hline $\mathbf{3}$ & Acute heamolytic Reaction & 49 & 11.6 \\
\hline $\mathbf{4}$ & Volume overload & 38 & 9.0 \\
\hline $\mathbf{5}$ & hypotension & 21 & 4.9 \\
\hline $\mathbf{6}$ & Allergic anaplylaxis & 9 & 2.1 \\
\hline & Total & $\mathbf{4 2 1}$ & $\mathbf{1 0 0}$ \\
\hline
\end{tabular}

Table 2: Acute reactions were seen in 421 patients $(26.3 \%)$ most of the complications are mild with no record of fatalities

\begin{tabular}{|l|c|c|}
\hline & Reaction & No reaction \\
\hline Full Crossmatch & 326 & 1092 \\
\hline Uncross match/Not Full Cross Match & 95 & 89 \\
\hline Total & $\mathbf{4 2 1}$ & $\mathbf{1 1 8 1}$ \\
\hline
\end{tabular}

Odd ratio 3.58, $\mathrm{Cl}$ 95\%, $\mathrm{p}=1.0000$.

Table 3: There is no statistical difference between a blood that was cross match fully for 2 hours as against uncross match but same ABO blood group or cross match blood for less than 2 hours

\begin{tabular}{|cc|c|c|}
\hline \multicolumn{2}{|c|}{ Parity } & Reactions & No reaction \\
\hline Primip & & 78 & 286 \\
\hline Multip & & 343 & 895 \\
\hline & Total & $\mathbf{4 2 1}$ & $\mathbf{1 1 8 1}$ \\
\hline
\end{tabular}

Odd ratio $0.71, \mathrm{X}^{2} 5.40, \mathrm{Cl}=95 \% \mathrm{p}<0.05$

Table 4: Multigrividae are more likely to develop acute transfusion reaction than primigrividae

rate in the study population is $10.5 \%$ which is higher than the $6 \%$ reported for United Kingdom [7]. Blood transfusion rate of $37 \%$ have been reported for obstetrics emergencies in developing countries. Acute transfusion reactions were seen in 421 patients (26.3\%) which is higher than the $20 \%$ reported in the literature [2]. This may be because the study population is homogenous (Pregnant) with peculiar characteristics such as physiological changes in pregnancy which may affect immunity, previous history of blood transfusion in addition to effect of the loss of blood which necessitated the transfusion.

Multiparous women may form alloantibodies to leukocyte, red cells or platelet antigens as a result of an overt or inapparent fetal - maternal heammorrhage. Women who form leukocyte antibodies following pregnancy are more likely to have febrile non hemolytic transfusion reactions if subsequently transfused with leukocyte containing blood components [8]. $86 \%$ of the subjects in this study are multiparous.

Like in the general population, febrile nonhemolytic transfusion reactions (FNHTR) are more common than acute allergic reactions (AAR) $[9,10]$. In this study FNHTR account for $47.7 \%$ while AAR account for $11.6 \%$.

Multigravidity is a risk factor as against primigravidity (Table 4), presumably, due to sensitization and subsequent formation of antibiotics resulting from feto-maternal transfusion that may occur in previous pregnancies.

In the study centre, Obstetrics emergencies are common, and the tendency to have shortage of blood is not uncommon, therefore transfusion of uncross match blood or sub cross match $\mathrm{ABO}$ compatible blood ( 30 minutes to 1 hour instead of 2 hours) cross match is practiced. No statistical difference was found between the two groups (Table 3 ) which means that in extreme emergencies, such practice may continue.

There is a statistically significant relationship in developing transfusion reactions between pregnant women with previous history of transfusion and those without (see result above), this is similar to what was reported in Kano, North Western, Maiduguri, North Eastern and Ife, South Western Nigeria [11-13].

Blood banking is crucial in blood transfusion services, and a lot has been said about stored blood and its possible effects which include depletion of clotting factors and development of transfusion reaction $[11,14]$. The longer the length of storage, the higher the risk of reaction, which was also found in our study to be statistically significant. In the present study, only whole blood and packed cells were transfused, as we don't have facilities that segregate the different components of the 
Citation: Ibrahim UN, Garba N, Tilde IM (2013) Acute Blood Transfusion Reactions in Pregnancy, an Observational Study from North Eastern Nigeria. J Blood Disorders Transf 4:145. doi:10.4172/2155-9864.1000145

blood, which may also increase the rate of the reactions. Transfusion related lung injury (TRALI) was not seen in this study probably it was not recognized [15].

\section{Conclusion}

Blood transfusion rate is high because alternatives are either not available or not practical to use in pregnancy.

Alternatives to blood transfusions such as autologous blood transfusion may not be practical in obstetrics emergencies [16,17]. Cell salvage machine is not available, others like Erythropoitin, purified or recombinant hemoglobin or perflourocabons are generally not available in poor resource settings, and therefore blood may be the only option where transfusion is indicated.

Acute transfusion reactions are common resulting from many factors such as physiology of pregnancy, high incidence of obstetrics complications requiring multiple and recurrent transfusions. There is a need for governments and nongovernmental organizations to provide transfusion alternatives at affordable rates, but more important is poverty eradication, women empowerment, availability of skilled health worker at delivery, female education etc. These will empower the pregnant mothers to seek medical help early so as to avoid blood transfusion and its complications. In dire emergency transfusion of uncross match $\mathrm{ABO}$ compatible blood may be life serving and where possible, avoidance of stored blood should be the practiced.

\section{References}

1. Paxton A, Maine D, Freedman L, Fry D, Lobis S (2005) The evidence for emergency obstetric care. Int J Gynaecol Obstet 88: 181-193.

2. Walker RH (1987) Special report: transfusion risks. Am J Clin Pathol 88: 374 378.

3. Fastman BR, Kaplan HS (2011) Errors in transfusion medicine: have we learned our lesson? Mt Sinai J Med 78: 854-864.
4. Cantwell R, Clutton-Brock T, Cooper G, Dawson A, Drife J, et al. (2011) Saving Mothers' Lives: Reviewing maternal deaths to make motherhood safer: 20062008. The Eighth Report of the Confidential Enquiries into Maternal Deaths in the United Kingdom. BJOG 118 Suppl 1: 1-203.

5. Mairiga AG, Saleh W (2009) Maternal mortality at the State Specialist Hospital Bauchi, Northern Nigeria. East Afr Med J 86: 25-30.

6. WHO/heamovigilance.

7. Catling S (2007) Blood conservation techniques in obstetrics: a UK perspective Int J Obstet Anesth 16: 241-249.

8. Eder AF, Dy BA. (2009) Effective reduction of TRALI risk with plasma Collected predominantly from male donors. Transfusion, 49 supp: 459.

9. Climent-Peris C, Vélez-Rosario R (2001) Immediate transfusion reactions. P R Health Sci J 20: 229-235.

10. Squires JE (2011) Risks of transfusion. South Med J 104: 762-769.

11. Gwaram BA, Borodo MM, Dutse Al, Kuliya Gwarzo (2012) Pattern of acute blood transfusion reactions in Kano, North Western Nigeria. Niger J. Basic clin sci 9: 27-32

12. Ahmed SG, Ibrahim UA, Gamas MG, Incidence and clinical pattern of immune mediated blood transfusion reactions in Maiduguri Nigeria. Nig. J. Basic Clin Sci, 2004 1: 5-9.

13. Arewa OP, Akinola NO, Salawu L (2009) Blood transfusion reactions; evaluation of 462 transfusions at a tertiary hospital in Nigeria. Afr J Med Med Sci 38: 143148

14. Muylle L, Wouters E, De Bock R, Peetermans ME (1992) Reactions to platele transfusion: the effect of the storage time of the concentrate. Transfus Med 2 : 289-293.

15. Skeate RC, Eastlund T (2007) Distinguishing between transfusion related acute lung injury and transfusion associated circulatory overload. Curr Opin Hemato 14: $682-687$

16. Liumbruno GM, Liumbruno C, Rafanelli D (2012) Autologous blood in obstetrics: where are we going now? Blood Transfus 10: 125-147.

17. Brecher ME, Goodnough LT (2002) The rise and fall of preoperative autologous blood donation (editorial). Transfusion 42: 1618-1622.
Citation: Ibrahim UN, Garba N, Tilde IM (2013) Acute Blood Transfusion Reactions in Pregnancy, an Observational Study from North Eastern Nigeria. J Blood Disorders Transf 4:145. doi:10.4172/2155-9864.1000145 